\title{
Superficial temporal artery to middle cerebral artery bypass: past, present, and future
}

\author{
Marcelo D. Vilela, M.D., ${ }^{1}$ AND DaVID W. Newell, M.D. ${ }^{2}$ \\ ${ }^{\prime}$ Department of Neurological Surgery, Harborview Medical Center, University of Washington; \\ and ${ }^{2}$ Swedish Neuroscience Institute, Swedish Medical Center, Seattle, Washington
}

\begin{abstract}
Object. The aim of this study was to review the historical developments and current status of superficial temporal artery (STA) to middle cerebral artery (MCA) bypass.

Method. A literature review was performed to review the origins and current uses of the STA bypass procedure in neurosurgery.

Results. The idea of providing additional blood supply to the brain to prevent stroke and maintain neurological function has been present in the mind of neurosurgeons for many decades. In 1967 the first STA-MCA bypass was done by M. G. Yaşargil, and an enormous step was made into the field of microneurosurgery and cerebral revascularization. During the decades that followed, this technique was used as an adjuvant or a definitive surgical treatment for occlusive disease of the extracranial and intracranial cerebral vessels, skull base tumors, aneurysms, carotid-cavernous fistulas, cerebral vasospasm, acute cerebral ischemia, and moyamoya disease. With the results of the first randomized extracranial-intracranial (EC-IC) bypass trial and the development of endovascular techniques such as angioplasty for intracranial atherosclerotic disease and cerebral vasospasm, the indications for STA-MCA bypass became limited. Neurosurgeons continued to perform EC-IC bypasses as an adjuvant to clipping of aneurysms and in the treatment of skull base tumors and moyamoya disease; the procedure is less commonly used for atherosclerotic carotid artery occlusion (CAO) with definite evidence of hemodynamic insufficiency. The evidence that patients with symptomatic CAO and "misery perfusion" have an increased stroke risk has prompted a second trial for evaluating EC-IC bypass for stroke prevention. The Carotid Occlusion Surgery Study is a new trial designed to determine whether STA-MCA bypass can reduce the incidence of stroke in these patients. New trials will also reveal the role of the STA-MCA bypass in the prevention of hemorrhages in moyamoya disease.

Conclusions. The role of STA-MCA bypass in the management of cerebrovascular disease continues to be refined and evaluated using advanced imaging techniques and by performing randomized trials for specific purposes, including symptomatic CAO. (DOI: 10.3171/FOC/2008/24/2/E2)
\end{abstract}

\section{KEY WORDS - bypass surgery - neurosurgical history • superficial temporal artery-middle cerebral artery bypass}

\section{$\mathrm{T}$} HE introduction of microvascular surgery to neurosurgery was made possible by the combined efforts and ideas of a few surgeons during the 1960-1970 decade. Some of the first pioneers were surgeons in Burlington, Vermont. Jacobson and Suarez, ${ }^{56}$ who were using the microscope to repair vessels in small animals according to the principles and techniques introduced by Alexis Carrel, were successful in achieving a $100 \%$ patency rate after reconstructing the carotid arteries of 20 dogs and 6 rabbits by using 7-0 atraumatic silk.

In the Division of Neurosurgery at the University of

Abbreviations used in this paper: $\mathrm{CAO}=$ carotid artery occlusion; $\mathrm{CT}=$ computed tomography; EC-IC = extracranial-intracranial; $\mathrm{ICA}=$ internal carotid artery; $\mathrm{MCA}=$ middle cerebral artery; $\mathrm{OEF}=$ oxygen extraction fraction; PET = positron emission tomography; $\mathrm{rCBF}=$ regional cerebral blood flow; $\mathrm{SAH}=$ subarachnoid hemorrhage; STA = superficial temporal artery.
Vermont, R. M. P. Donaghy was very interested in the field of microvascular surgery as well. ${ }^{57,135} \mathrm{He}$ had established a microsurgical laboratory in which he pursued intensive studies on arterial vasospasm and small-vessel reconstruction in small animals. Using meticulous techniques, microinstruments, and the surgical microscope, he was successful in reconstructing vessels $<1 \mathrm{~mm}$ in diameter. ${ }^{135}$

Working with Dr. Krayenbuhl in the Department of Neurosurgery in Zurich, M. G. Yaşargil also became very interested in the neurosurgical applications of microvascular surgery. His interest was further stimulated when he was asked to perform an embolectomy of a cortical artery, a technique he had not yet mastered. ${ }^{133}$ Dr. Senning, a cardiovascular surgeon, encouraged him to pursue a technique that would enable such a procedure to be performed. His enthusiasm to learn techniques of cerebral revascularization increased after the report of an EC-IC bypass in a patient who had an occluded ICA at the neck. ${ }^{131}$ Professor 


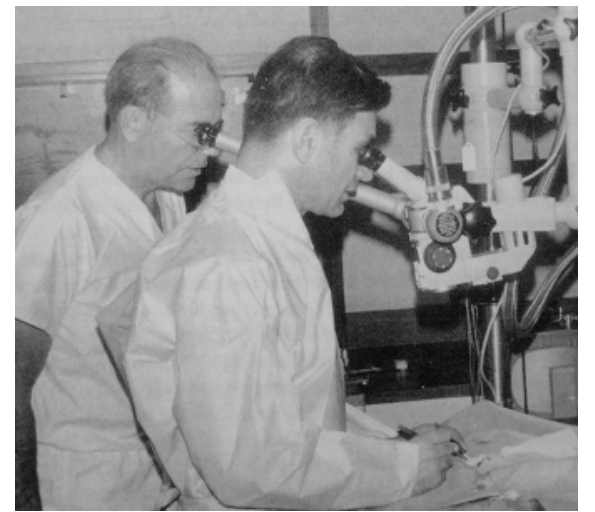

FIG. 1. Photograph showing M. Gazi Yaşargil (right) with his mentor, Peardon Donaghy (left), while performing microvascular surgery in the laboratory at the University of Vermont. Photograph reproduced with permission from M. G. Yaşargil.

Yaşargil then began looking for a position in which he could train in microvascular techniques, and during the International Congress of Neuroradiologists meeting in 1964, Drs. William Sweet and Theodore Rasmussen advised him to contact Professor Donaghy. Professor Yaşargil eventually visited Professor Donaghy's laboratory in Burlington, Vermont, and began his training in microvascular techniques in 1965 (Fig. 1). His initial training involved the use of the operating microscope, microinstruments, and microvascular techniques while experimenting on the femoral and carotid arteries of small animals. ${ }^{134}$ In 1966, the purchase of a bipolar coagulator-designed by Dr. L. Malis - together with the availability of 9-0 sutures allowed a major advance in the development of microsurgical revascularization, enabling the dissection of intracranial structures in a clean field and meticulous repair of intracranial vessels. ${ }^{135}$ Initial attempts by Yaşargil included a technique to interpose a femoral vascular graft from the common carotid artery to the MCA, as a form of EC-IC bypass, in small animals. Unfortunately, the graft would progress to thrombosis early after the procedure. The idea of performing a bypass from the STA to the MCA was then born. By the end of $1966>30$ such operations in dogs had been performed, and the technique was later described in detail in a paper. ${ }^{16}$

Professor Yaşargil returned to Zurich and performed the first STA-MCA bypass on October 30, 1967, in a patient with Marfan syndrome and complete occlusion of the MCA. ${ }^{135,136}$ He later published a paper describing the first 9 cases in which an STA-MCA bypass had been performed, 7 for occlusion of the ICA or MCA and 2 as an adjuvant to the surgical treatment of complex intracranial aneurysms. ${ }^{135}$ The feasibility of creating an EC-IC shunt was then demonstrated, and a major step was made into the field of reconstructive intracranial vascular microneurosurgery (Fig. 2).

\section{The Past}

\section{Acute Stroke and Emergent Cerebral Revascularization}

The idea of performing an emergent cerebral revascularization procedure for acute ischemic stroke was very rational when based on the knowledge of ischemic thresholds

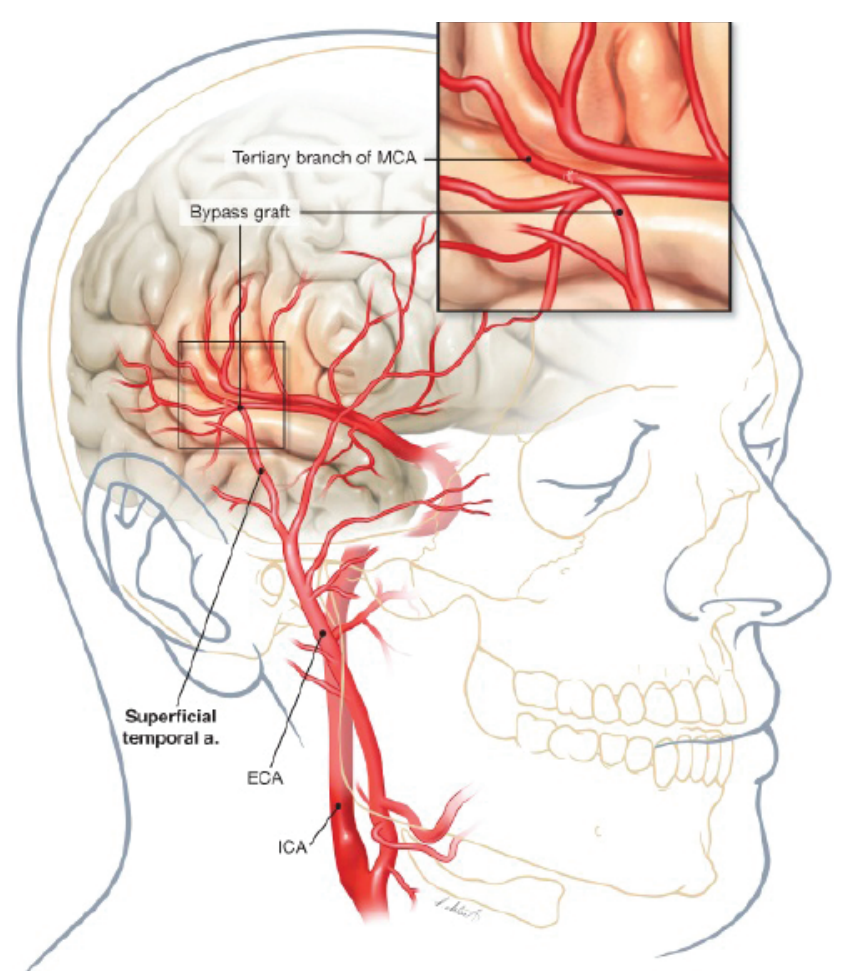

FIG. 2. Illustration depicting a completed STA-MCA. Note the frontoparietal branch of the STA, connected to a distal surface branch of the MCA, immediately after it emerges from the distal portion of the sylvian fissure. a. = artery; ECA = external carotid artery.

for infarction and the concept of ischemic penumbra. ${ }^{15}$ Providing additional blood flow to areas of the brain in which the rCBF was low enough to decrease cellular function but not low enough to induce an infarction was very attractive. Encouraging results were reported by some, but others considered the event of acute cerebral ischemia a relative contraindication for an emergent bypass, given the poor results and high rate of complications..$^{15,19,36}$ Crowell, ${ }^{15}$ working with Jafar, conducted a literature analysis and found 67 cases in which an emergency STA-MCA bypass had been performed in the setting of acute cerebral ischemia. The condition in 27 patients was improved after the procedure and unchanged in 26; 11 patients died. Crowell and Jafar pointed out that more data were needed for firm indications, and only those patients with crescendo transient ischemic attacks or mild to moderate deficits $<6$ hours' duration with no infarction on imaging studies should be considered for an EC-IC bypass.

Subsequently, with the advent of interventional neuroradiology and thrombolytic therapies using tissue plasminogen activator and urokinase, ${ }^{12,80}$ the indications for performing an emergent EC-IC bypass for acute ischemic stroke decreased..$^{96}$

\section{Cerebral Vasospasm and SAH}

For decades cerebral vasospasm has been the leading cause of delayed ischemic neurological deficit and a significant factor contributing to poor outcome following aneurysmal SAH. The STA-MCA bypass has been performed to augment blood flow to ischemic areas of the 
Superficial temporal artery-middle cerebral artery bypass

brain affected by vasospasm in an attempt to prevent stroke and improve neurological outcome. Batjer and Samson ${ }^{10}$ reported on 11 patients who had undergone an STA-MCA bypass in the setting of symptomatic vasospasm. Six patients improved in the first 24 hours after surgery and 2 others had stabilized deficits. Benzel and Kesterson ${ }^{11}$ also reported encouraging results and a reversal of neurological deficits in a patient with medically refractory symptomatic vasospasm treated with an STA-MCA bypass. This indication for the procedure did not gain wide acceptance, however. The introduction and development of endovascular techniques by interventional radiologists, such as balloon angioplasty with or without papaverine combined with hypertension, hypervolemia, hemodilution therapy, assumed a pivotal role in the management of symptomatic severe vasospasm. ${ }^{25,26}$

\section{Occlusive Cerebrovascular Disease Not Amenable to Carotid Endarterectomy}

The first STA-MCA bypass in a patient with occlusive cerebrovascular disease was performed by Yaşargil. Subsequently, his results in the first 7 patients who had undergone an STA-MCA bypass for occlusive cerebrovascular disease of the ICA or MCA were published in detail. ${ }^{135,136}$

Several neurosurgery leaders around the world soon mastered this elegant technique, and within a few years hundreds of procedures already had been performed. The procedure was still considered experimental though, given absent proof of efficacy in preventing future stroke and its uncertain indications. ${ }^{126}$ Nevertheless, good to excellent results were obtained in the early cases, promising possible benefits in the prevention of stroke, with a high bypass patency rate and low morbidity and death. ${ }^{103,120,126,130,137}$ Subsequently, large studies also demonstrated the feasibility of the STA-MCA bypass and possible neurological improvement in patients with atherosclerotic occlusive cerebrovascular disease, including bilateral disease. ${ }^{14,24,35,121}$

By the end of a decade after the introduction of the STA-MCA bypass to the neurosurgical community, the selection of patients and the indications for surgery remained controversial despite attempts to refine the surgical indications based on the concept of hemodynamic insufficiency. ${ }^{41,107,112}$ Our knowledge of the natural history of occlusive cerebrovascular disease was rather uncertain, and methods for the identification of hemodynamic cerebrovascular insufficiency were still evolving. Moreover, postoperative results had always been compared with the preoperative status in the same patients and not to the natural course of the disease in a randomized control group. ${ }^{22}$

In 1977 the North American EC-IC Bypass Study was begun by Dr. Henry Barnett and colleagues to compare the best medical therapy with the STA-MCA bypass plus medical therapy in patients with symptomatic occluded or highgrade stenotic atherosclerotic lesions of the MCA or ICA not amenable to endarterectomy. ${ }^{22}$ The objective of the study was to determine whether an STA-MCA anastomosis would decrease the incidence of stroke and stroke-related death in those patients. There were 714 patients randomized to the best medical treatment and 663 patients to an STA-MCA bypass plus the best medical therapy. The 30-day surgical mortality and major stroke morbidity rates were 0.6 and $2.5 \%$, respectively. In the surgical group, fatal and nonfatal stroke occurred earlier and more frequently. The investigators concluded that the STA-MCA bypass was ineffective in preventing cerebral ischemia in patients with atherosclerotic disease of the MCA and ICA not amenable to endarterectomy. ${ }^{22}$ A temporary functional deterioration in several routine daily tasks was also observed during the 1st month of posttreatment in the surgical group, but the difference was not significant at the 6-month follow-up. ${ }^{45}$ Even though the study was considered exemplary because of its impeccable methods and follow-up, ${ }^{93}$ several members of the neurosurgical community criticized the results on the following points: 1) Only half of the patients were receiving antiplatelet agents at the time of entry into the study and the other half were not receiving any medical therapy. ${ }^{5}$ 2) Patients were not evaluated preoperatively in terms of their cerebrovascular hemodynamic status. Patients with symptoms due to hemodynamic insufficiency, the group that would most benefit from a bypass augmentation procedure, were therefore not differentiated from those with symptoms caused by thromboembolic mechanisms. ${ }^{4,5} 3$ ) Both the patient and the therapist were not blinded and, therefore, the potential for underreporting or overreporting was possible..$^{5}$ 4) Randomization-to-treatment bias could have occurred, in which a large number of patients randomized to surgery had major morbidity events that happened before the operation.,17 5) There were no angiographic determinants for entry. The severity of stenosis was not measured, and vertebral artery angiography was not performed in all patients. ${ }^{4} 6$ ) A large percentage of patients had no symptoms between the angiographic demonstration of ICA occlusion and randomization. ${ }^{5,17}$ 7) A large number of patients underwent surgery outside the study. ${ }^{4}$ 8) A high percentage of patients had tandem lesions demonstrated on angiography, which may be a condition not very suitable for a bypass. ${ }^{4,17}$

Further conclusions from the EC-IC bypass study were later published in a paper addressing those criticisms and once more provided evidence to support the results of the trial. ${ }^{7}$ Subsequently, a committee appointed by the American Association of Neurological Surgeons was then encouraged to examine the study with an emphasis on 2 aspects: the randomized trial proper and patients who underwent surgery outside of the trial. ${ }^{34}$ Within the randomized trial proper, none of the issues was believed by the committee and study investigators to be relevant to the point that it would compromise either the design of the trial or any conclusions of the study. Regarding the number of patients who underwent surgery outside of the trial, research done by Sundt ${ }^{119}$ indicated that at least 2500 patients had a bypass done outside the study in participating centers. ${ }^{34}$ Some of these patients were eligible for the trial and some were not. This issue raised the concern of whether the EC-IC bypass trial conclusions could or could not be generalizable to the entire population at risk for stroke. ${ }^{119}$ Due to a lack of sufficient data this question could not be answered correctly. The study investigators also pointed out that randomized trials involve only a small fraction of the population at risk and that this factor does not prevent a study from being valid. ${ }^{8}$

Following the publication of the EC-IC bypass trial conclusions, there was a marked decrease in the number of STA-MCA bypasses performed for cerebrovascular occlusive disease. ${ }^{2}$ Cerebral revascularization continued to be 
performed mainly for the treatment of moyamoya disease and as an adjuvant for major parent vessel occlusion during surgical treatment of complex intracranial aneurysms and skull base tumors. ${ }^{91}$

\section{The Present}

\section{Aneurysms and Tumors}

The treatment of cerebral aneurysms has been evolving since the 19th century, when occlusion of the ICA in the neck was used to promote obliteration of the sac by a decrease in flow and eventual thrombosis. Carotid artery ligation remained the mainstay for the treatment of some intracranial aneurysms of the anterior circulation..$^{84,95}$ The results of the Cooperative Study of Intracranial Aneurysms and SAH with regard to the treatment of intracranial aneurysms by occlusion of the carotid artery in the neck were subsequently published. ${ }^{84}$ The overall incidence of ischemic neurological deficits was 33\% in patients with ruptured aneurysms and $12 \%$ in those with unruptured lesions. The ischemic deficit rate was also higher in patients with occlusion of the ICA as opposed to the common carotid artery (abrupt occlusion: 59 vs 32\%, respectively; gradual occlusion: $41 \mathrm{vs} 24 \%$, respectively), irrespective of the presence or absence of an SAH.

Following Yaşargil's description of an STA-MCA bypass in 2 patients who harbored giant intracranial aneurysms of the supraclinoid ICA, ${ }^{135}$ the option of an EC-IC bypass became a component in the neurosurgeon's armamentarium for the treatment of complex intracranial aneurysms.

The importance of the STA-MCA bypass in preventing ischemic neurological deficits during major parent vessel occlusion for the treatment of intracranial aneurysms has been well established. ${ }^{21,29,37,49,65,70,94,96,106,109,115,116,122,141}$ The utility of revascularization with an STA-MCA bypass has also been shown during the repair of mycotic or traumatic aneurysms of distal cortical vessels, trauma to the cervical ICA, surgical repair of carotid-cavernous fistulas, or removal of skull base tumors. ${ }^{13,23,30,43,58,90,113,128}$ The presence of a patent STA-MCA bypass may not offer complete protection from ischemia, however, when a major intracranial or extracranial vessel has been occluded. . $0,29,37,46,49,90,117$ Possible mechanisms of ischemia include embolic phenomena, failure to provide enough blood supply to the entire MCA territory, and retrograde thrombosis of the $\mathrm{M}_{1}$ segment when the MCA is clipped just proximal to its bifurcation..$^{20,37}$, $46,49,94,95,106$ Based on an analysis of the known risks of the balloon occlusion test, ${ }^{92}$ de novo aneurysm formation,,${ }^{58}$ possible contralateral aneurysm enlargement, and the fact that some patients who pass a CAO test will still suffer an ischemic event, ${ }^{74,77,92,118,129}$ some neurosurgeons have adopted the approach of performing an EC-IC bypass in all cases that require sacrifice of a major cerebral vessel. ${ }^{58,73,101}$ Others will perform a bypass based on the analysis of clinical, angiographic, and balloon occlusion test results. ${ }^{6,42,83,124}$ Nevertheless, the use of an EC-IC bypass as part of the treatment of complex aneurysms has been adopted by most cerebrovascular surgeons.

\section{Moyamoya Disease}

The first case of moyamoya disease treated with a direct
STA-MCA bypass was performed in 1972 by Yaşargil in a 4-year-old child, who had remarkable improvement following the procedure. ${ }^{66}$ Postoperative angiograms showed patency of the anastomosis and evidence of collateral vessels from the vertebrobasilar system and other extracranial sources. In 1980 an indirect STA-MCA bypass for bilateral occlusion of the supraclinoid ICA was performed in a patient with recurrent symptoms of hemiparesis and aphasia. ${ }^{114}$ A direct STA-MCA bypass was planned, but at surgery no suitable recipient cortical vessel was found, and the STA and surrounding tissue were basically laid over the cerebral hemisphere and sutured to the arachnoid. The patient had a remarkable clinical recovery, and postoperative angiograms showed extensive collateral vessel formation, establishing the effectiveness of an indirect STA-MCA bypass as a form of cerebral revascularization.

In children, the benefits of improving symptoms, reversing neurological deficits, enabling the development of normal intelligence, preventing further ischemic episodes, decreasing seizure activity, and even the disappearance of involuntary movements have been observed. $3.33,48,52,54,59,60,75$, $89,102,123$ Several studies addressing the efficacy of the direct and indirect bypass techniques have been done in pediatric patients, and better clinical and angiographic results are usually seen when a direct bypass is performed. . $^{32,54,75,123}$

Various studies have also demonstrated the benefits of an STA-MCA bypass in ischemic moyamoya disease in adults, preventing further ischemic episodes and improving clinical symptoms and cerebral hemodynamics. $28,44,50,51,59,61$, ${ }^{68,79,88}$ On the other hand, the effectiveness of revascularization in preventing hemorrhage remains a controversy. ${ }^{50,53,61,88}$

A large retrospective study including 57 neurosurgical institutions has been done in Japan, and data were available for 290 patients with the hemorrhagic form of moyamoya disease. ${ }^{27}$ Conservative treatment was administered to 138 patients, and 152 patients underwent surgical revascularization. In the nonsurgical group, $28.3 \%$ of the patients had a recurrent hemorrhage during follow-up, compared with $19.1 \%$ in the surgical group. The authors concluded that prospective studies are needed to clarify the efficacy of the STA-MCA bypass in the prevention of hemorrhage in this disease. A large prospective trial is now underway in Japan to evaluate the effectiveness of STA-MCA bypass for the prevention of cerebral hemorrhage in moyamoya disease. $^{52,78,140}$

\section{Occlusive Cerebrovascular Disease}

After the EC-IC bypass trial results appeared, a few centers continued to perform this bypass surgery for the treatment of symptomatic occlusion of the ICA in selected patients, with good outcomes. Indications for the procedure were based on evidence of perfusion abnormalities on imaging studies or the presence of symptoms despite maximal medical management. ${ }^{2,55,64,76,81,85,108,125}$

With advances in neuroimaging and a better understanding of cerebral metabolism, more investigations were performed in an effort to determine the natural history of occlusive atherosclerotic carotid artery disease, the risk of stroke in subpopulations with different states of hemodynamic insufficiency, and whether any of these subpopulations could benefit from a revascularization procedure. ${ }^{38}$, $47,62,97$ 
The occurrence of ischemic symptoms and stroke in occlusive cerebrovascular disease can usually be attributed to either thromboembolic phenomena or a decrease in cerebral perfusion pressure..$^{9,62,99}$ Only recently the overall risk of subsequent stroke in patients with $\mathrm{CAO}$ has been clarified. A major prospective study by Powers et al. ${ }^{97}$ revealed a stroke risk of $0 \%$ at 2 years and $4.4 \%$ at 3 years in the group of patients who never had any symptoms in contrast to a risk of $7.7 \%$ at 1 year, $19 \%$ at 2 years, and $21 \%$ at 3 years after symptom onset in symptomatic patients with CAO. Additionally, several authors using different imaging modalities, such as xenon-CT, xenon-single-photon emission CT, or PET scanning, have provided evidence that the presence of hemodynamic impairment of the cerebral blood flow/perfusion is significantly linked to an increased risk of stroke. ${ }^{62,69,86,132,139}$

The St. Louis Carotid Occlusion Study ${ }^{18,38,97}$ was a prospective blinded study in which the authors evaluated the relationship between the state of "misery perfusion" (increased OEF on PET scanning) and stroke risk in patients with symptomatic CAO. There were 81 patients who were divided in 2 groups: patients with increased OEF (39 patients) and those with a normal OEF (42 patients). In all patients with an increased OEF, the hemodynamic abnormality was ipsilateral to the occluded carotid artery. At the end of the follow-up, in the group with an increased OEF, there were 12 total and 11 ipsilateral strokes, compared with 3 total and 2 ipsilateral strokes in the group with a normal OEF ( $p=0.005$ and 0.004 , respectively). The risk of ipsilateral stroke in the group with an increased OEF was 10.6 and $26.5 \%$ at 1 and 2 years after symptom onset, respectively. On the other hand, the group with a normal OEF had a 2.4 and $5.3 \%$ risk of stroke at 1 and 2 years after symptom onset, respectively. The authors concluded that the state of misery perfusion is a significant independent predictor of the subsequent risk of stroke in medically treated patients with CAO. This study also led to the conclusion that patients with retinal symptoms only had a low risk of subsequent stroke, ${ }^{97}$ a result also found in other studies. ${ }^{63}$

Several investigators have described the effects of an STA-MCA bypass on $\mathrm{rCBF}$, regional cerebral metabolic rate of oxygen, cerebral blood volume, and $\mathrm{OEF}$ in patients with occlusive cerebrovascular disease. More importantly, there was a demonstrable reversal of misery perfusion and marked improvements in $\mathrm{rCBF}$ and cerebral metabolism in the subpopulation of patients with hemodynamic impairment who had undergone a revascularization procedure. $9,31,41,55,64,72,98,104,108,125,127,138$

\section{The Future}

\section{Acute Stroke and Emergent Cerebral Revascularization}

New imaging modalities were developed for the evaluation of acute stroke during the past decade, and the differentiation between regions of acute infarction and those with low flow (ischemic penumbra) is now possible with a combination of diffusion-weighed MR imaging, perfusionweighted MR imaging, perfusion CT/CT angiography, and PET scanning. ${ }^{100,105,110,111}$ Within the penumbral zone, it may also be possible to predict the areas that will become infarcted without reperfusion compared with those regions that will most likely survive even without reperfusion. ${ }^{105,110}$
Recent anecdotal case reports on emergent surgical revascularization for acute stroke have demonstrated restoration of normal flow to regions of ischemic penumbra and improvement in perfusion-weighted MR imaging/diffusionweighted MR imaging mismatch. ${ }^{67,87}$ Even though the area of mismatch does not accurately correspond to the penumbral zone, ${ }^{110}$ with further developments in imaging modalities and better definitions of ischemic but viable tissue (increased OEF) thresholds, there will likely be more thoughts on emergent surgical revascularization procedures for acute stroke in cases in which intraarterial thrombolysis is contraindicated.

\section{Aneurysms and Tumors}

The STA-MCA bypass as an adjuvant for aneurysm treatment will likely remain an option in the future. The procedure has been used successfully as an adjuvant to aneurysm or parent vessel occlusion by surgical and endovascular means. The threshold of lowered rCBF indicating that the collateral circulation will be inadequate to prevent ischemia after permanent major vessel occlusion is still to be determined. ${ }^{71}$ Advanced brain imaging perfusion technologies may improve the accuracy of the balloon occlusion test. Newer imaging modalities may also allow a more accurate prediction of whether certain aneurysms can be clipped safely or whether wall thickness and the presence of calcification mandates parent vessel occlusion/reconstruction combined with an EC-IC bypass as an adjuvant. New STA-MCA bypass techniques ${ }^{82}$ may be useful in certain circumstances when a 2-limb end-to-end bypass with good blood flow and a short anastomotic time are needed.

\section{Moyamoya Disease}

The role of the STA-MCA bypass in moyamoya disease awaits the results of large randomized trials. As mentioned, previous studies have indicated improved metabolic and hemodynamic outcomes in patients with this disease. More detailed outcome studies on the prevention of ischemic stroke and hemorrhagic events in adult patients are also expected. The Japan Adult Moyamoya Trial will be conducted to determine whether EC-IC bypass plus risk factor modifications are effective in reducing the incidence of hemorrhagic phenomena and improve outcome in patients with this disease. ${ }^{78}$ The efficacy of the STA-MCA bypass in children will also be better defined when the results of large long-term outcome studies become available.

\section{Occlusive Cerebrovascular Disease}

The evidence that patients with CAO and Stage 2 hemodynamic insufficiency have an increased risk of stroke and the substantiation that an EC-IC bypass may reverse this stage of misery perfusion reveals the need for a new prospective randomized trial. ${ }^{38,39}$

The Carotid Occlusion Surgery Study ${ }^{1,40}$ is a new trial in which investigators will prospectively evaluate the efficacy of the STA-MCA bypass in the prevention of stroke in patients with symptomatic CAO and evidence of misery perfusion on PET scans. It will be a multicenter randomized trial, and the EC-IC bypass will have a primary objective of augmenting blood flow to the cerebral hemisphere that is hemodynamically impaired by an ipsilateral occlusion of the ICA. The trial will enroll only those patients 
who have symptoms of the cerebral hemisphere referable to the occluded ICA, and all patients will receive the best medical therapy. Patients with retinal symptoms will not be enrolled unless they have hemispheric symptoms as well. The primary outcome event of the study is the occurrence of ipsilateral ischemic hemispheric stroke from the time of randomization to the end of the follow-up at 24 months or any stroke or death within 40 days of entry into the trial. Secondary end points include any fatal or nonfatal stroke, ipsilateral disabling stroke, death, quality of life, and function. Other outcome events include transient ischemic attack, surgical complications other than stroke, perioperative myocardial infarction, and bleeding complications.

\section{Conclusions}

The STA-MCA bypass is an elegant procedure developed by M. G. Yaşargil and was first applied in the treatment of occlusive cerebrovascular disease in 1967. It was soon added to the surgical management of other complex vascular lesions of the nervous system. It has proved to be feasible with a low complication rate but has been shown to be ineffective in preventing stroke in nonselected populations harboring occlusive carotid artery or MCA disease. The finding that a subpopulation of patients with symptomatic CAO and increased OEF has an increased risk of stroke, together with the evidence that an STA-MCA bypass procedure can reverse the state of misery perfusion brings us to a new trial. The Carotid Occlusion Surgery Study will be performed to determine whether the STA-MCA bypass can decrease the incidence of stroke in these patients with evidence of misery perfusion. An international multicenter trial will probably further define the role of the STA-MCA bypass in the setting of hemorrhagic moyamoya disease. This elegant surgical technique will likely remain an important tool in the neurosurgeon's armamentarium for the management of occlusive atherosclerotic and traumatic cerebrovascular disease, intracranial aneurysms, skull base tumors, moyamoya disease, and possibly acute stroke.

\section{Disclaimer}

None of the authors received any financial support for the completion of this study.

\section{References}

1. Adams HP Jr, Powers WJ, Grubb RL Jr, Clark WR, Woolson RF: Preview of a new trial of extracranial-to-intracranial arterial anastomosis: the carotid occlusion surgery study. Neurosurg Clin $\mathbf{N}$ Am 12:613-624, 2001

2. Amin-Hanjani S, Butler WE, Ogilvy CS, Carter BS, Barker FG II: Extracranial-intracranial bypass in the treatment of occlusive cerebrovascular disease and intracranial aneurysms in the United States between 1992 and 2001: a population-based study. J Neurosurg 103:794-804, 2005

3. Amine ARC, Moody RA, Meeks W: Bilateral temporal-middle cerebral artery anastomosis for Moyamoya syndrome. Surg Neurol 8:3-6, 1977

4. Ausman JI, Diaz FG: Critique of the extracranial-intracranial bypass study. Surg Neurol 26:218-221, 1986

5. Awad IA, Spetzler RF: Extracranial-intracranial bypass surgery: a critical analysis in light of the International Cooperative study. Neurosurgery 19:655-664, 1986
6. Barnett DW, Barrow DL, Joseph GJ: Combined extracranialintracranial bypass and intraoperative balloon occlusion for the treatment of intracavernous and proximal carotid artery aneurysms. Neurosurgery 35:92-98, 1994

7. Barnett HJM, Fox A, Hachinski V, Haynes B, Peerless SJ, Sackett $\mathrm{D}$, et al: Further conclusions from the extracranial-intracranial bypass trial. Surg Neurol 26:227-235, 1986

8. Barnett HJM, Sackett D, Taylor DW, Haynes B, Peerless SJ, Meissner I, et al: Are the results of the extracranial-intracranial bypass trial generalizable? N Engl J Med 316:820-824, 1987

9. Baron JC, Bousser MG, Rey A, Guillard A, Comar D, Castaigne P: Reversal of focal "Misery-perfusion syndrome" by extra-intracranial arterial bypass in hemodynamic cerebral ischemia. A case study with 150 positron emission tomography. Stroke 12: 454-459, 1981

10. Batjer H, Samson D: Use of extracranial-intracranial bypass in the management of symptomatic vasospasm. Neurosurgery 19:235246, 1986

11. Benzel EC, Kesterson L: Extracranial-intracranial bypass surgery for the management of vasospasm after subarachnoid hemorrhage. Surg Neurol 30:231-234, 1988

12. Broderick JP, Hacke W. Treatment of acute ischemic stroke. Part I: Recanalization strategies. Circulation 106:1563-1569, 2002

13. Burke JP, Marion DW: Cerebral revascularization in trauma and carotid occlusion. Neurosurg Clin N Am 12:595-611, 2001

14. Chater N: Neurosurgical extracranial-intracranial bypass for stroke: with 400 cases. Neurol Res 5:1-9, 1983

15. Crowell RM: Emergency cerebral revascularization. Clin Neurosurg 33:281-305, 1986

16. Crowell RM, Yaşargil MG: End-to-side anastomosis of superficial temporal artery to middle cerebral artery branch in the dog. Neurochirurgia 16:73-77, 1973

17. Day AL, Rhoton AL Jr, Little JR: The extracranial-intracranial bypass study. Surg Neurol 26:222-226, 1986

18. Derdeyn CP, Yundt KD, Videen TO, Carpenter DA, Grubb RL Jr, Powers WJ: Increased oxygen extraction fraction is associated with prior ischemic events in patients with carotid occlusion. Stroke 29:754-758, 1998

19. Diaz FG, Ausman JI, Mehta B, Dujovny M, de los Reyes RA, Pearce J, et al: Acute cerebral revascularization. J Neurosurg 63: 200-209, 1985

20. Diaz FG, Ausman JI, Pearce JE: Ischemic complications after combined internal carotid artery occlusion and extracranial-intracranial anastomosis. Neurosugery 10:563-570, 1982

21. Diaz FG, Umansky F, Mehta B, Montoya S, Dujovny M, Ausman JI, et al: Cerebral revascularization to a main limb of the middle cerebral artery in the Sylvian fissure. An alternative approach to conventional anastomosis. J Neurosurg 63:21-29, 1985

22. The EC-IC Bypass Study Group: Failure of extracranial-intracranial arterial bypass to reduce the risk of ischemic stroke. Results of an international randomized trial. N Engl J Med 313:11911200, 1985

23. Eguchi T, Mayanagi Y, Hanamura T, Tanaka H, Ohmori K, Takakura K: Treatment of bilateral spontaneous carotid-cavernous fistula by Hamby's method combined with an extracranial-intracranial bypass procedure. Neurosurgery 11:706-711, 1982

24. el-Fiki M, Chater NL, Weinstein PR: Results of extracranial-intracranial arterial bypass for bilateral carotid occlusion. J Neurosurg 63:521-525, 1985

25. Elliot JP, Newell DW, Lam DJ, Eskridge JM, Douville CM, Le Roux PD, et al: Comparison of balloon angioplasty and papaverine infusion for the treatment of vasospasm following aneurysmal subarachnid hemorrhage. J Neurosurg 88:277-284, 1998

26. Eskridge JM, Newell DW, Pendleton GA: Transluminal angioplasty for treatment of vasospasm. Neurosurg Clin N Am 1: 387-399, 1990

27. Fujii K, Ikezaki K, Irikura K, Miyasaka Y, Fukui M: The efficacy of bypass surgery for the patients with hemorrhagic moyamoya disease. Clin Neurol Neurosurg 99: S194-S195 1997 
28. Fukui M: Guidelines for the diagnosis and treatment of spontaneous occlusion of the circle of Willis ('moyamoya' disease). Research Committee on Spontaneous Occlusion of the Circle of Willis (Moyamoya Disease) of the Ministry of Health and Welfare, Japan. Clin Neurol Neurosurg 99:S238-S240, 1997

29. Gelber BR, Sundt TM Jr: Treatment of intracavernous and giant carotid aneurysms by combined internal carotid ligation and extra- to intracranial bypass. J Neurosurg 52:1-10, 1980

30. Gewertz BL, Samson DS, Ditmore QM, Bone GE: Management of penetrating injuries of the internal carotid artery at the base of the skull utilizing extracranial-intracranial bypass. J Trauma 20: 365-369, 1980

31. Gibbs JM, Wise RJ, Thomas DJ, Mansfield AO, Russell RW: Cerebral hemodynamic changes after extracranial-intracranial bypass surgery. J Neurol Neurosurg Psychiatry 50:140-150, 1987

32. Goda M, Isono M, Ishii K, Kamida T, Abe T, Kobayashi H: Longterm effects of indirect bypass surgery on collateral vessel formation in pediatric moyamoya disease. J Neurosurg 100 ( 2 Suppl Pediatrics):156-162, 2004

33. Golby AJ, Marks MP, Thompson RC, Steinberg GK: Direct and combined revascularization in pediatric moyamoya disease. Neurosurgery 45:50-60, 1999

34. Goldring S, Zervas N, Langfitt T: The Extracranial-Intracranial Bypass Study. A report of the committee appointed by the American Association of Neurological Surgeons to examine the study. N Engl J Med 316:817-820, 1987

35. Gratzl O, Muller HR: Indications for bilateral bypass operations. Neurosurg Rev 5:73-75, 1982

36. Gratzl O, Schmiedek P, Spetzler RF, Steinhoff H, Marguth F: Clinical experience with extra-intracranial arterial anastomosis in 65 cases. J Neurosurg 44:313-324, 1976

37. Grote E, Schönmayr R: Extracranial-intracranial bypass in giant aneurysms. Neurosurg Rev 5:83-85, 1982

38. Grubb RL Jr, Derdeyn CP, Fritsch SM, Carpenter DA, Yundt KD, Videen TO, et al: Importance of hemodynamic factors in the prognosis of symptomatic carotid occlusion. JAMA 280:1055-1060, 1998

39. Grubb RL Jr, Powers WJ: Risks of stroke and current indications for cerebral revascularization in patients with carotid occlusion. Neurosurg Clin N Am 12:473-487, 2001

40. Grubb RL Jr, Powers WJ, Derdeyn CP, Adams HP Jr, Clarke WR: The Carotid Occlusion Surgery Study. Neurosurg Focus 14(3): E9, 2003

41. Grubb RL Jr, Ratcheson RA, Raichle ME, Kliefoth AB, Gado $\mathrm{MH}$ : Regional cerebral blood flow and oxygen utilization in superficial temporal-middle cerebral artery anastomosis patients: an exploratory definition of clinical problems. J Neurosurg 50: 733-741, 1979

42. Hacein-Bey L, Connolly ES Jr, Duong H, Vang MC, Lazar RM, Marshall RS, et al: Treatment of inoperable carotid aneurysms with endovascular carotid occlusion after extracranial-intracranial bypass surgery. Neurosurgery 41:1225-1234, 1997

43. Hadley MN, Spetzler RF, Martin NA, Johnson PC: Middle cerebral artery aneurysm due to Nocardia asteroides: case report of aneurysm excision and extracranial-intracranial bypass. Neurosurgery 22:923-928, 1988

44. Han DH, Kwon OK, Byun BJ, Choi BY, Choi CW, Choi JU, et al: A co-operative study: clinical characteristics of 334 Korean patients with moyamoya disease treated at neurosurgical institutes (1976-1994). The Korean Society for Cerebrovascular Disease. Acta Neurochir 142: (Wien)1263-1274, 2000

45. Haynes RB, Mukherjee J, Sackett DL, Taylor DW, Barnett HJM, Peerless SJ: Functional status changes following medical or surgical treatment for cerebral ischemia. Results of the extracranialintracranial bypass study. JAMA 257:2043-2046, 1987

46. Heros RC: Thromboembolic complications after combined internal carotid ligation and extra-to-intracranial bypass. Surg Neurol 21:75-79, 1984
47. Hirano T, Minematsu K, Hasegawa Y, Tanaka Y, Hayashida K, Yamaguchi T: Acetazolamide reactivity on 123I-IMP single photon emission computed tomography in patients with major cerebral artery occlusive disease: correlation with positron emission tomography parameters. J Cereb Blood Flow Metab 14:763770, 1994

48. Holbach KH, Wassman H, Wappenschmidt J: Superficial temporal-middle cerebral artery anastomosis in Moyamoya disease. Acta Neurochir (Wien) 52:27-34, 1980

49. Hopkins LN, Grand W: Extracranial-intracranial arterial bypass in the treatment of aneurysms of the carotid and middle cerebral arteries. Neurosurgery 5:21-31, 1979

50. Houkin K, Kamiyama H, Abe H, Takahashi A, Kuroda S: Surgical therapy for adult moyamoya disease. Can surgical revascularization prevent the recurrence of intracerebral hemorrhage? Stroke 27:1342-1346, 1996

51. Houkin K, Kuroda S, Ishikawa T, Abe H: Neovascularization (angiogenesis) after revascularization in moyamoya disease. Which technique is most useful for moyamoya disease? Acta Neurochir (Wien) 142:269-276, 2000

52. Houkin K, Kuroda S, Nakayama N: Cerebral revascularization for moyamoya disease in children. Neurosurg Clin N Am 12:575584,2001

53. Ikezaki K, Fukui M, Inamura T, Kinukawa N, Wakai K, Ono Y: The current status of the treatment for hemorrhagic type moyamoya disease based on a 1995 nationwide survey in Japan. Clin Neurol Neurosurg 99 (2 Suppl):S183-S186, 1997

54. Ishikawa T, Houkin K, Kamiyama H, Abe H: Effects of surgical revascularization on outcome of patients with pediatric moyamoya disease. Stroke 28:1170-1173, 1997

55. Iwama T, Hashimoto N, Hayashida K: Cerebral hemodynamic parameters for patients with neurological improvements after extracranial-intracranial arterial bypass surgery: evaluation using positron emission tomography. Neurosurgery 48: 504-512, 2001

56. Jacobson JH, Suarez EL: Microsurgery in anastomosis of small vessels. Surg Forum 11:243-245, 1960

57. Jacobson JH II, Wallman LJ, Schumacher GA, Flanagan M, Suarez EL, Donaghy RM: Microsurgery as an aid to middle cerebral artery endarterectomy. J Neurosurg 19:108-115, 1962

58. Javedan SP, Deshmukh VR, Spetzler RF, Zabramski JM: The role of cerebral revascularization in patients with intracranial aneurysms. Neurosurg Clin N Am 36:541-555, 2001

59. Karasawa J, Kiruchi H, Furuse S, Kawamura J, Sakaki T: Treatment of moyamoya disease with STA-MCA anastomosis. J Neurosurg 49:679-688, 1978

60. Karasawa J, Touho H, Ohnishi H, Miyamoto S, Kikuchi H: Longterm follow-up study after extracranial-intracranial bypass surgery for anterior circulation ischemia in childhood moyamoya disease. J Neurosurg 77:84-89, 1992

61. Kawagushi S, Okuno S, Sakaki T: Effect of direct arterial bypass on the prevention of future stroke in patients with the hemorrhagic variety of moyamoya disease. J Neurosurg 93:397-401, 2000

62. Klijn CJM, Kappelle J, Tulleken CAF, van Gijn J: Symptomatic carotid artery occlusion. A reappraisal of hemodynamic factors. Stroke 28:2084-2093, 1997

63. Klijn CJM, Kappelle LJ, van Huffelen AC, Visser GH, Algra A, Tulleken CAF, et al: Recurrent ischemia in symptomatic carotid occlusion: prognostic value of hemodynamic factors. Neurology 55:1806-1812, 2000

64. Kobayashi H, Kitai R, Ido K, Kabuto M, Handa Y, Kubota T, et al: Hemodynamic and metabolic changes following cerebral revascularization in patients with cerebral occlusive diseases. Neurol Res 21:153-160, 1999

65. Kodama N, Suzuki J: Bypass surgery in the treatment of aneurysms. Neurosurg Rev 5:87-90, 1982

66. Krayenbühl HA: The moyamoya syndrome and the neurosurgeon. Surg Neurol 4:353-360, 1975

67. Krishnamurthy S, Tong D, McNamara KP, Steinberg GK, Cock- 
roft KM: Early carotid endarterectomy after ischemic stroke improves diffusion/perfusion mismatch on magnetic resonance imaging: report of two cases. Neurosurgery 52:238-241, 2003

68. Kuroda S, Houkin K, Kamiyama H, Abe H: Effects of surgical revascularization on peripheral aneurysms in Moyamoya disease: report of three cases. Neurosurgery 49:463-468, 2001

69. Kuroda S, Houkin K, Kamiyama H, Mitsumori K, Iwasaki Y, Abe $\mathrm{H}$ : Long-term prognosis of medically treated patients with internal carotid or middle cerebral artery occlusion: can acetazolamide test predict it? Stroke 32:2110-2116, 2001

70. Lansen TA, Kasoff SS, Arguelles JH: Giant pediatric aneurysm treated with ligation of the middle cerebral artery with the Drake tourniquet and extracranial-intracranial bypass. Neurosurgery 25:81-85, 1989

71. Latchaw RE, Yonas H, Hunter GJ, Yuh WT, Ueda T, Sorensen $\mathrm{AG}$, et al: Guidelines and recommendations for perfusion imaging in cerebral ischemia. A scientific statement for healthcare professionals by the writing group on perfusion imaging, from the Council on Cardiovascular Radiology of the American Heart Association. Stroke 34:1084-1104, 2003

72. Laurent JP, Lawner PM, O'Connor M: Reversal of intracerebral steal by STA-MCA anastomosis. J Neurosurg 57:629-632, 1982

73. Lawton MT, Hamilton MG, Morcos JJ, Spetzler RF: Revascularization and aneurysm surgery: current techniques, indications, and outcome. Neurosurgery 38:83-94, 1996

74. Linskey ME, Jungreis CA, Yonas H, Hirsch WL Jr, Sekhar LN, Horton JA, et al: Stroke risk after abrupt internal carotid sacrifice: accuracy of preoperative assessment with balloon test occlusion and stable xenon-enhanced CT. AJNR Am J Neuroradiol 15: 829-843, 1994

75. Matsushima T, Inoue T, Suzuki SO, Fujii K, Fukui M, Hasuo K: Surgical treatment of moyamoya disease in pediatric patientscomparison between the results of indirect and direct revascularization procedures. Neurosurgery 31:401-405, 1992

76. Mendelowitsch A, Taussky P, Rem JA, Gratzl O: Clinical outcome of standard extracranial-intracranial bypass surgery in patients with symptomatic atherosclerotic occlusion of the internal carotid artery. Acta Neurochir (Wien) 146:95-101, 2004

77. Miller JD, Jawad K, Jennett B: Safety of carotid ligation and its role in the management of intracranial aneurysms. J Neurol Neurosurg Psychiatry 40:64-72, 1977

78. Miyamoto S, Japan Adult Moyamoya Trial Group: Study design for a prospective randomized trial of extracranial-intracranial bypass surgery for adults with moyamoya disease and hemorrhagic onset - the Japan Adult Moyamoya Trial Group. Neurol Med Chir 44:218-219, 2004

79. Morimoto M, Iwama T, Hashimoto N, Kojima A, Hayashida K: Efficacy of direct revascularization in adult Moyamoya disease: haemodynamic evaluation by positron emission tomography. Acta Neurochir (Wien) 141:377-384, 1999

80. The National Institute of Neurological Disorders and Stroke rtPAStroke Study Group: Tissue plasminogen activator for acute ischemic stroke. N Engl J Med 333:1581-1587, 1995

81. Neff KW, Horn P, Dinter D, Vajkoczy P, Schmiedek P, Düber C: Extracranial-intracranial arterial bypass surgery improves total brain blood supply in selected symptomatic patients with unilateral internal carotid artery occlusion and insufficient collateralization. Neuroradiology 46:730-737, 2004

82. Newell DW, Dailey AT, Skirboll SL: Intracranial vascular anastomosis using the microanastomotic system. Technical note. J Neurosurg 89:676-681, 1998

83. Newell DW, Skirboll SL: Revascularization and bypass procedures for cerebral aneurysms. Neurosurg Clin N Am 9:697-711, 1998

84. Nishioka H: Results of the treatment of intracranial aneurysms by occlusion of the carotid artery in the neck. J Neurosurg 25: 660-704, 1966

85. Nussbaum ES, Erickson DL: Extracranial-intracranial bypass for ischemic cerebrovascular disease refractory to maximal medical therapy. Neurosurgery 46:37-43, 2000

86. Ogasawara K, Ogawa A, Yoshimoto T: Cerebrovascular reactivity to acetazolamide and outcome in patients with symptomatic internal carotid or middle cerebral artery occlusion: a xenon-133 single-photon emission computed tomography study. Stroke 33: 1857-1862, 2002

87. Ogasawara K, Sasaki M, Tomitsuka N, Kubo Y, Inoue T, Ogawa A: Early revascularization in a patient with perfusion computed tomography/diffusion-weighted magnetic resonance imaging mismatch secondary to acute vertebral artery occlusion. Case report. Neurol Med Chir 45:306-310, 2005

88. Okada Y, Shima T, Nishida M, Yamane K, Yamada T, Yamanaka C: Effectiveness of superficial temporal artery-middle cerebral artery anastomosis in adult moyamoya disease: cerebral hemodynamics and clinical course in ischemic and hemorrhagic varieties. Stroke 29:625-630, 1998

89. Olds MV, Griebel RW, Hoffman HJ, Craven M, Chuang S, Schutz H: The surgical treatment of childhood moyamoya disease. J Neurosurg 66:675-680, 1987

90. Olteanu-Nerbe V, Marguth F: Extracranial-intracranial bypass operation in basal tumors. Neurosurg Rev 5:99-105, 1982

91. Onesti ST, Solomon RA, Quest DO: Cerebral revascularization: a review. Neurosurgery 25:618-629, 1989

92. Origitano TC, al-Mefty O, Leonetti JP, DeMonte F, Reichman $\mathrm{OH}$ : Vascular considerations and complications in cranial base surgery. Neurosurgery 35:352-363, 1994

93. Peerless SJ: Indications for the extracranial-intracranial arterial bypass in light of the EC-IC bypass study. Clin Neurosurg 33: 307-326, 1986

94. Peerless SJ, Ferguson GG, Drake CG: Extracranial-intracranial (EC/IC) bypass in the treatment of giant intracranial aneurysms. Neurosurg Rev 5:77-81, 1982

95. Peerless SL, Hampf CR: Extracranial to intracranial bypass in the treatment of aneurysms. Clin Neurosurg 32:114-154, 1985

96. Pikus HJ, Heros RC: Stroke: indications for emergent surgical intervention. Clin Neurosurg 45:113-127, 1997

97. Powers WJ, Derdeyn CP, Fritsch SM, Carpenter DA, Yundt KD, Videen TO, et al: Benign prognosis of never-symptomatic carotid occlusion. Neurology 54:878-882, 2000

98. Powers WJ, Martin WRW, Herscovitch P, Raichle ME, Grubb RL Jr: Extracranial-intracranial bypass surgery: hemodynamic and metabolic effects. Neurology 34:1168-1174, 1984

99. Powers WJ, Raichle ME: Positron emission tomography and its application to the study of cerebrovascular disease in man. Stroke 16:361-376, 1985

100. Røhl L, Ostergaard L, Simonsen CZ, Vestergaard-Poulsen P, Andersen G, Sakoh M, et al: Viability thresholds of ischemic penumbra of hyperacute stroke defined by perfusion-weighted MRI and apparent diffusion coefficient. Stroke 32:11401146, 2001

101. Roski RA, Spetzler RF: Carotid ligation, in Wilkins RH, Rengachary SS (eds): Neurosurgery, ed 2. New York: McGrawHill, 1996, pp 2333-2340

102. Sakamoto K, Kitano S, Yasui T, Komiyama M, Nishikawa M, Iwai Y, et al: Direct extracranial-intracranial bypass for children with moyamoya disease. Clin Neurol Neurosurg 99 (2 Suppl):S128-S133, 1997

103. Samson DS, Hodosh RM, Clark WK: Microsurgical treatment of transient cerebral ischemia. Preliminary results in 50 patients. JAMA 241:376-378, 1979

104. Samson Y, Baron JC, Bousser MG, Rey A, Derlon JM, David $P$, et al: Effects of extra-intracranial arterial bypass on cerebral blood flow and oxygen metabolism in humans. Stroke 16:609-616, 1985

105. Schaefer PW, Ozsunar Y, He J, Hamberg LM, Hunter GJ, Sorensen AG, et al: Assessing tissue viability with MR diffusion and perfusion imaging. AJNR Am J Neuroradiol 24: 436-443, 2003 
106. Schaps P, Mikulin HD: Extracranial-intracranial bypass in inoperable carotid aneurysms and none reconstructive occluded cavernous fistulas. Neurosurg Rev 5:91-93, 1982

107. Schmiedek P, Gratzl O, Spetzler RF, Steinhoff H, Enzenbach R, Brendel W, et al: Selection of patients for extra-intracranial arterial bypass surgery based on rCBF measurements. J Neurosurg 44:303-312, 1976

108. Schmiedek P, Piepgras A, Leinsinger G, Kirsch CM, Einhüpl K: Improvement of cerebrovascular reserve capacity by EC-IC arterial bypass surgery in patients with ICA occlusion and hemodynamic cerebral ischemia. J Neurosurg 81:236-244, 1994

109. Sengupta RP: Special indications of external/internal bypass operation. Neurosurg Rev 5:107-112, 1982

110. Sobesky J, Zaro Weber O, Lehnhardt FG, Hesselmann V, Neveling M, Jacobs A, et al: Does the mismatch match the penumbra? Magnetic resonance imaging and positron emission tomography in early ischemic stroke. Stroke 36:980-985, 2005

111. Sobesky J, Zaro Weber O, Lehnhardt FG, Hesselmann V, Thiel A, Dohmen C, et al: Which time-to-peak threshold best identifies penumbral flow? A comparison of perfusion-weighted magnetic resonance imaging and positron emission tomography in acute ischemic stroke. Stroke 35:2843-2847, 2004

112. Spetzler RF: Extracranial-Intracranial arterial anastomosis for cerebrovascular disease. Surg Neurol 11:157-161, 1979

113. Spetzler RF, Owen MP: Extracranial-Intracranial arterial bypass to a single branch of the middle cerebral artery in the management of a traumatic aneurysm. Neurosurgery 4:334-337, 1979

114. Spetzler RF, Roski RA, Kopaniky DR: Alternative superficial temporal artery to middle cerebral artery revascularization procedure. Neurosurgery 7:484-487, 1980

115. Spetzler RF, Roski RA, Schuster H, Takaoka Y: The role of ECIC in the treatment of giant intracranial aneurysms. Neurol Res 2:345-359, 1980

116. Spetzler RF, Schuster H, Roski RA: Elective extracranial-intracranial arterial bypass in the treatment of inoperable giant aneurysms of the internal carotid artery. J Neurosurg 53: 22-27, 1980

117. Spetzler RF, Selman W, Carter LP: Elective EC-IC bypass for unclippable intracranial aneurysms. Neurol Res 6:64-68, 1984

118. Sugawara Y, Kikuchi T, Ueda T, Nishizaki M, Nakata S, Mochizuki T, et al: Usefulness of brain SPECT to evaluate brain tolerance and hemodynamic changes during temporary balloon occlusion test and after permanent carotid occlusion. J Nucl Med 43:1616-1623, 2002

119. Sundt TM Jr: Was the international randomized trial of extracranial-intracranial bypass representative of the population at risk? N Engl J Med 316:814-816, 1987

120. Sundt TM Jr, Siekert RG, Piepgras DG, Sharbrough FW, Houser OW: Bypass surgery for vascular disease of the carotid system. Mayo Clin Proc 51:677-692, 1976

121. Sundt TM Jr, Whisnant JP, Fode NC, Piepgras DG, Houser OW: Results, complications, and follow-up of 415 bypass operations for occlusive disease of the carotid system. Mayo Clin Proc 60:230-240, 1985

122. Suzuki S, Takahashi T, Ohkuma H, Shimizu T, Fujita S: Management of giant serpentine aneurysms of the middle cerebral artery-review of literature and report of a case successfully treated by STA-MCA anastomosis only. Acta Neurochir (Wien) 117:23-29, 1992

123. Suzuki Y, Negoro M, Shibuya M, Yoshida J, Negoro T, Watanabe K: Surgical treatment for pediatric moyamoya disease: use of the superficial temporal artery for both areas supplied by the anterior and middle cerebral arteries. Neurosurgery 40: 324-330, 1997

124. Swearingen B, Heros RC: Common carotid occlusion for unclippable carotid aneurysms: an old but still effective operation. Neurosurgery 21:288-295, 1987
125. Takagi Y, Hashimoto N, Iwama T, Hayashida K: Improvement of oxygen metabolic reserve after extracranial-intracranial bypass surgery in patients with severe haemodynamic insufficiency. Acta Neurochir (Wien) 139:52-57, 1997

126. Tew JM Jr: Reconstructive intracranial vascular surgery for prevention of stroke. Clin Neurosurg 22:264-280, 1975

127. Tsuda Y, Kimura K, Iwata Y, Hayakawa T, Etani H, Fukunaga $\mathrm{R}$, et al: Improvement of cerebral blood flow and/or $\mathrm{CO} 2$ reactivity after superficial temporal artery-middle cerebral artery bypass in patients with transient ischemic attacks and watershed-zone infarctions. Surg Neurol 22:595-604, 1984

128. Vishteh AG, Marciano FF, David CA, Schievink WI, Zabramski JM, Spetzler RF: Long-term graft patency rates and clinical outcomes after revascularization for symptomatic traumatic internal carotid artery dissection. Neurosurgery 43:761-768, 1998

129. Walker BS, Mathews D, Batjer H, Allen BC, Purdy PD: Detection of cerebral hypoperfusion during trial carotid occlusion with reversal following extracranial-intracranial bypass prior to permanent occlusion. Clin Nucl Med 19:499-503, 1994

130. Whisnant JP, Sundt TM Jr, Fode NC: Long-term mortality and stroke morbidity after superficial temporal artery-middle cerebral artery bypass operation. Mayo Clin Proc 60:241-246, 1985

131. Woringer E, Kunlin J: [Anastomosis between the common carotid and the intracranial carotid or the sylvian artery by a graft, using the suspended suture technic.] Neurochirurgie 200:181-188, 1963 (Fr)

132. Yamauchi H, Fukuyama H, Nagahama Y, Nakamura K, Yamamoto Y, Konishi J, et al: Evidence of misery perfusion and risk for recurrent stroke in major cerebral arterial occlusive diseases from PET. J Neurol Neurosurg Psychiatry 61:18 25, 1996

133. Yaşargil MG: History of microneurosurgery, in Spetzler RF, Carter LP, Selman WR, et al (eds): Cerebral Revascularization for Stroke. New York: Thieme-Stratton, 1985, pp 292298

134. Yaşargil MG: A legacy of microneurosurgery: memoirs, lessons, and axioms. Neurosurgery 45:1025-1092, 1999

135. Yaşargil MG: Microsurgery Applied To Neurosurgery. Stuttgart: Georg Thieme, 1969

136. Yaşargil MG, Krayenbuhl HA, Jacobson JH II: Microneurosurgical arterial reconstruction. Surgery 67:221-233, 1970

137. Yaşargil MG, Yonekawa Y: Results of microsurgical extraintracranial arterial bypass in the treatment of cerebral ischemia. Neurosurgery 1:22-24, 1977

138. Yonas H, Gur D, Good BC, Latchaw RE, Wolfson SK Jr, Good WF, et al: Stable xenon CT blood flow mapping for evaluation of patients with extracranial-intracranial bypass surgery. J Neurosurg 62:324-333, 1985

139. Yonas H, Smith HA, Durham SR, Pentheny SL, Johnson DW: Increased stroke risk predicted by compromised cerebral blood flow reactivity. J Neurosurg 79:483-489, 1993

140. Yoshida Y, Yoshimoto T, Shirane R, Sakurai Y: Clinical course, surgical management and long-term outcome of moyamoya patients with rebleeding after an episode of intracerebral hemorrhage: an extensive follow-up study. Stroke 30:2272-2276, 1999

141. Zumstein B, Yaşargil MG, Curcic M, Nauta HJW: Experiences with the extra- to intracranial bypass in the surgical management of cerebral aneurysms ( 9 cases). Neurol Res 2:327-343, 1980

Manuscript submitted November 13, 2007.

Accepted November 21, 2007.

Address correspondence to: David W. Newell, M.D., Swedish Neuroscience Institute, Swedish Medical Center, 550 17th Avenue, Suite \#500, Seattle, Washington 98122. email: david.newell@ swedish.org. 